\title{
O CONSERVADORISMO PRESENTE NA LEGISLAÇÃO BRASILEIRA E A MANEIRA QUE É REFLETIDO NO ABORTO ${ }^{1}$
}

CONSERVATIVES IN BRAZILIAN LEGISLATION AND THE WAY THAT IS REFLECTED IN

ABORTION

Luiza Taveira LEONI ${ }^{2}$

ISSUE DOI: 10.21207/2675-0104.2019.916

\begin{abstract}
RESUMO
A presente pesquisa científica se insere na área de Direito Civil e também Criminal, com o intuito de destacar os conceitos de pessoa e sua dignidade, e como a legislação se desenvolve em relação a interrupção voluntária da gravidez, mais especificamente como os direitos da gestante são abordados, como determinadas posicionamentos jurisprudenciais possuem argumentos favoráveis para a mulher grávida, visto que a atual Constituição Federal Brasileira garante o direito à vida e também a dignidade humana. No entanto, quando se trata de analisar a situação da maneira que ela realmente ocorre, acaba sendo um pouco diferente, principalmente quando se trata da realidade de mulheres com situações econômicas menos favorecidas. Neste caso, vários obstáculos são encontrados, pois não possuem condições financeiras para que façam o procedimento do aborto de forma segura, o que as leva a recorrer a clínicas despreparadas, ocasionando, na maioria das vezes, lesões graves na gestante, ou até mesmo a sua morte. Esse estudo foi feito através de pesquisas históricas, e da leitura de doutrinas atuais de Direito Civil. Tal pesquisa foi realizada pelo intermédio de doutrinas, livros, revistas, textos normativos e artigos científicos, conduzindo a um conhecimento antes inexistente sobre o assunto.. Como resultados desta pesquisa nota-se que é de extrema importância o conhecimento aprofundado sobre a definição e conceito de pessoa, a necessidade de conhecer o principio da dignidade humana, e como a legislação e o posicionamento jurisprudencial aborda e define o aborto.
\end{abstract}

Palavras-chave: Aborto; Gestante; Dignidade da Pessoa Humana; Princípio da Autodeterminação.

\footnotetext{
${ }^{1} \mathrm{O}$ presente artigo sintetiza a monografia de conclusão da pesquisa, realizada para o Programa Interno de Bolsas de Iniciação Científica (PIBIC 2018-2019) da Faculdade de Direito de Franca (FDF), Franca/SP.

${ }^{2}$ Discente da Faculdade de Direito de Franca (FDF), Franca/SP. Bolsista do Programa Interno de Bolsas de Iniciação Científica (PIBIC 2018-2019).
} 


\begin{abstract}
The present research is about civil right and also criminal, in order to highlight the concept of person and it dignity, how the legislation develops about the abortion, more specifically how are the pregnant rights approchead, how certains case law have favorable arguments for pregnant woman, whereas the current Federal Constitution guarantees the right to the life and also human dignity. However, when analyzing the real situation, turns to be a little different, specialy when it comes to poor women reality. In this cases, several obstacles are found, because they have no money to perform the procedure in the right and safe ways, using unprepared clinics, resulting, most of the times, in serious injury to the pregnant woman, or even your death. This study was done through research and reading current civil law doctrines. As results of this research is it possible to realize the importance of in-depth knowledge about the concept and definition of person, the human dignity principle, and how legislation defines and addresses abortion.
\end{abstract}

Keywords: Abortion; Pregnancy; Dignity of Human Person; Principle of Self-ordination.

$\mathrm{Na}$ realidade brasileira, são notórios os problemas que se vem tendo em relação ao aborto, e como algumas das gestantes encontram dificuldades e falta de amparo com relação a esta pratica. O aborto, apesar de ser criminalizado no país, acontece de forma recorrente, porém, não tão segura na grande maioria das vezes. $\mathrm{O}$ aborto realizado em clínicas clandestinas, e não devidamente preparadas pode acabar resultando em sérias consequiências para a saúde e vida da gestante.

A pesquisa em tela teve como tema principal a "O conservadorismo presente na legislação Brasileira e a maneira que é refletido no aborto". A priori, foi necessário um entendimento acerca do assunto, e sobre os direitos presentes na Constituição Federal, o conceito de pessoa, o início da personalidade, o princípio da autodeterminação e da dignidade da pessoa humana, para poder entender e relacionar o que deveria ser assegurado pela Lei, com o que realmente acontece na vida dessas mulheres.

A criminalização do aborto é uma barreira que as mulheres se deparam com grande freqüência. Visto que apesar de existir uma legislação que proíba tal procedimento, ele vem ocorrendo, e de maneira segura para aquelas que possuem condições financeiras favoráveis, e de maneia não segura para aquelas que possuem condições financeiras desfavoráveis.

Justifica-se a elaboração desta pesquisa pela quantidade de casos em que mulheres morrem em tentativas de aborto, não amparadas pela justiça, com abortos feitos de forma incorreta e em clinicas clandestinas. Apesar da criminalização do aborto, é grande o número de mulheres que o 
realizam quando se deparam com uma gravidez indesejada. No entanto, a mulher pertencente a classe média, possui condições de realizar um aborto seguro, enquanto uma mulher pertencente à classes mais baixas enfrenta condições precárias e desumanas na realização do procedimento, podendo deixá-las com seqüelas ou muitas vezes levando-as a morte.

A legalização do aborto não aumentaria a quantidade de casos, que como se vê, ocorre com bastante freqüência, traria uma diminuição no número de mortes e melhores condições para as mulheres que os desejarem fazer. Tendo em vista os países que descriminalizaram, como a França, que apresentam dados da diminuição do número de mulheres que desejam abortar e consequentemente do número de mortes.

O Estado brasileiro, desde a Constituição da República de 1891, é definido como Estado laico, independente da igreja, e prima pelo direito de exercício de todas as religiões. Com a promulgação da Constituição Cidadã de 1988, proclamou a liberdade de religião, e a separação total entre e igreja e Estado. Porém, ainda assim, a igreja possui grande influência nas decisões a respeito da realização do aborto.

A partir do momento em que a Igreja Católica e outros grupos religiosos, através de seus poderes históricos, mobilizam-se e contam com o apoio de parlamentares religiosos e conservadores, e conseguem impedir avanços legislativos no sentido de garantir os direitos humanos e as liberdades democráticas, o princípio do Estado laico se encontra violado

\section{ESTRUTURA NORMATIVA CONSTITUCIONAL EINFRACONSTITUCIONAL DO DIREITO DA PESSOA}

Pelo art. $2^{\circ}$ do Código Civil de 1916, todo homem é capaz de direitos e obrigações na ordem civil. Ou, no vigente Código: toda pessoa é capaz de direitos e deveres na ordem civil. Bastando, portanto, que o homem tenha nascido com vida, para que possa ser a ele atribuída personalidade, passando a ser sujeito de direito. Neste prisma, o nascituro, apesar de ainda não ter personalidade por não ter nascido, terá, no direito positivo brasileiro, seus direitos resguardados.

O conceito de personalidade jurídica deve ser entendida como a aptidão para adquirir direitos e também contrair obrigações, que deve ser juntamente exercida e regulada através da capacidade jurídica, encontrando-se a personalidade como terminologia genérica. Sendo a capacidade jurídica aquela que gera a aptidão para exercê-los nas 
obrigações da capacidade de fato, onde a aptidão pessoal para a prática dos atos que possuem efeitos jurídicos, a capacidade é a medida da personalidade, ela confere o limite da personalidade.

A personalidade jurídica é a projeção da personalidade íntima, psíquica de cada um. E social da personalidade psíquica com consequiências jurídicas.

Toda pessoa é dotada de personalidade, isto se explica no fato do ser humano ser o sujeito da relação jurídica. Porém, no decorrer da história, nem sempre foi assim, nem sempre toda pessoa foi sujeito de direitos, os escravos eram considerados coisas, sendo assim estavam fora do alcance da personalidade. Aquele que não é plenamente capaz necessita de outra pessoa que a substitua no campo jurídico, para que ela possa exercer seus direitos e contrair suas obrigações.

$\mathrm{O}$ direito à vida, o mais fundamental de todos, é um direito garantido por lei, assegurado pela Constituição Federal em seu artigo $5^{\circ}$, caput:

Art. $5^{\circ}$. Todos são iguais perante a lei, sem distinção de qualquer natureza, garantindo-se aos brasileiros e aos estrangeiros residentes no País a inviolabilidade do direito à vida, à liberdade, à igualdade, à segurança e à propriedade.

A dignidade é um atributo humano sentido e criado pelo homem, sendo este por ele desenvolvido e estudado. Pode-se afirmar que nunca houve um período em que não se houvesse a dignidade da pessoa humana, ela apenas não era reconhecida como atributo ou qualidade inata da pessoa.

A dignidade da pessoa humana é um conceito de extrema abrangência, explicando-se, por este motivo, a grande dificuldade de se formular um conceito jurídico a respeito. Seu sentido foi sendo criado e compreendido historicamente como valor.

A Constituição Federal de 1988 traz como fundamentos da República Federativa do Brasil e consequentemente, do Estado Democrático de Direito, a dignidade da pessoa humana.

É o que dispõe o art. $1^{\circ}$, III da Constituição Federal:

A República Federativa do Brasil, formada pela união indissolúvel dos Estados e Municípios e do Distrito Federal, constitui-se em Estado Democrático de Direito e tem como fundamentos: [...] III a dignidade da pessoa humana. 
Ao entender que não existe dignidade sem vida, da-se inicio a dignidade quando também da-se início à vida.

Desde a sua concepção, o nascituro é sujeito de direitos, como o direito à vida, não permitindo, a Constituição, nenhuma maneira de violálo, ou de legislar contra este direito, por ser ele fundamental.

No art. $2^{\circ}$ do Còdigo Civil esstá disposto que a personalidade civil da pessoa começa do nascimento com vida; mas a lei põe a salvo, desde a concepção, os direitos do nascituro.

Em seu artigo $6^{\circ}$ a Constituição Federal estabelece os direitos sociais da pessoa humana:

Art. $6^{\circ}$ São direitos sociais a educação, a saúde, a alimentação, o trabalho, a moradia, o transporte, o lazer, a segurança, a previdência social, a proteção à maternidade e à infância, a assistência aos desamparados, na forma desta Constituição.

Nota-se que o direito à saúde se encontra elencado como um dos direitos sociais à pessoa humana. Do mesmo modo, em seu Titulo VIII (Da ordem social), sua Seção II intitulada “Da Saúde”, seu artigo 196 dispõe:

Art. 196 A saúde é direito de todos e dever do estado, garantido mediante políticas sociais e econômicas que visem à redução do risco de doenças e de outros agravos e ao acesso universal e igualitário às ações e serviços para sua promoção, proteção e recuperação.

É nessa questão do direito a saúde que se encontra o questionamento entre a vida da mãe e a vida do feto, o conflito entre o direito à vida intrauterina e o direito da saúde e da autonomia reprodutiva da mulher. Não podendo esta ser vista como apenas um meio reprodutor, e chocando grande parte da população ao estabelecer a extinção de um embrião que ainda não veio a vida.

A Constituição Federal, ao não fazer qualquer tipo de especificação acerca da vida intrauterina ou extrauterina, deixa esse conceito aberto, deixando aberta a universalidade do direito a vida, e desta forma, não responde tal questionamento. Não valora tanto a vida da mãe, quanto a vida do feto, não da preferência por nenhuma das vidas no caso em conflito. 


\section{OS CONTORNOS DO ABORTO NA LEGISLAÇÃO BRASILEIRA}

No decorrer da história, em diferentes épocas e lugares, o aborto foi e vem sendo praticado de diversas maneiras, é assim também com a maneira como é visto ultimamente, em algumas épocas e regiões não o pune, porém, em outras, é duramente punido e castigado.

O tipo penal aborto é o de impedir o nascimento, por provocação. O resultado é o não nascimento por intenção do agente ou agentes. Sob a ótica civil, embora a lei ponha a salvo os direitos do nascituro, não há bem jurídico a ser protegido penalmente (vida e pessoa), porque estes só se consumam com o nascimento e a constatação da autonomia biológica do produto da concepção. Ausentes a estrutura do tipo, o bem jurídico, o objeto material, inexistente o crime ou delito. Em suma, é a constatação científica que se tem para delimitar o fim do estado potencial do produto da concepção e o início da personalidade civil.

O Código Criminal de 1830 foi o pioneiro a tratar o crime de aborto no Brasil, onde não se punia o delito praticado pela própria gestante, punia a conduta do agente, o terceiro, aquele que praticava o aborto na gestante com ou sem o seu consentimento. Esse crime estava incluído nos crimes contra a segurança da pessoa e da vida.

A pratica delitiva da gestante foi considerada crime apenas em 1890 com o Código Penal da República, havendo uma diferença entre o aborto que o feto era expulso do corpo ou não, e uma agravante no caso de morte da gestante.

Em 1940, com o Código Penal, que a pratica delitiva do aborto foi definida da maneira que se mantém até hoje, definida em sua parte especial, "Titulo I", que trata sobre os "Crimes Contra a Pessoa", e em seu capítulo I, do referido titulo, que trata sobre "Os Crimes Contra a Vida", de acordo com os artigos 124, 125, 126, 127 e 128 do atual Código Penal.

Apesar da proibição do aborto ter esta apenas duas exceções em lei, de acordo com o art. 128 do Código Penal, a pratica não é cessada totalmente, e por ser uma decisão que afeta a vida da mulher de diversas maneiras, muitas acabam optando pelo aborto, mesmo que este seja realizado de maneira clandestina e ilegal. E quando a gravidez não apresenta um risco de vida para a mulher, ou é resultante de um estupro, exceção em que o aborto também é permitido, as diversas outras consequências que englobam a vida da mulher são minimizadas, esquecidas e até deixadas de lado, como a sua dignidade, sua qualidade de 
vida e as consequências futuras que essa gravidez causará na vida dessa mulher.

No entanto, mesmo em face as situações em que o aborto é permitido por Lei, sua proibição nos demais casos é um caso polêmico, com diversos entendimentos de doutrinadores, entendimentos esses contrários e divergentes do da legislação ou não.

Em 2013, o Conselho Federal de Medicina, em um congresso interino, expressou o desejo da maioria, apontando a necessidade de reforma no atual Código Penal brasileiro, que ainda aguarda votação, com o intuito de afastar a ilicitude da interrupção da gravidez, quando resultado da vontade da gestante, até a $12^{\mathrm{a}}$ semana de gestação. Tal reforme é fundamentada sob a ética que considera a autonomia da mulher nos aspectos sociais, jurídicos, epidemiológicos e de saúde pública.

Tratando-se de aspectos constitucionais, depara-se com o seguinte questionamento: se a Lei maior de um país garante o direito à vida, além de classifica-lo como o mais fundamental dos direitos, como uma lei que não defende a vida de quem não consegue se defender poderá ser recebida? Como poderá haver uma ampliação nas hipóteses de impunibilidade ou até mesmo a exclusão do aborto provocado?

Tal questionamento ligado ao conceito de personalidade, que garante os direitos do nascituro desde a sua concepção, não facilita o discurso contrário aquele que está estabelecido na constituição e leis brasileiras. A opinião popular, sendo maioria contrária à prática, também dificulta as discussões a respeito da legalização.

Esmiuçadas as formas que a legislação brasileira aborda o aborto, e algumas de suas decisões sobre o referido assunto, vê-se que muito ainda precisa ser analisado, visto que é uma legislação criminal antiga, e novos tempos e circunstâncias exigem legislações que estejam de acordo com o que acontece na sociedade, para que não exista uma disparidade, principalmente se a desigualdade social for um fator que influencie nas decisões tomadas por aquelas em que a lei dispõe sobre. 


\section{O POSICIONAMENTO JURISPRUDENCIAL SOBRE A MULHER DECIDIR SOBRE A REALIZAÇÃO DO ABORTO}

No Brasil vive-se uma dramática realidade de milhares de mulheres, que, por não poderem se valer da Saúde Pública provocam a interrupção voluntária da gravidez que não podem ou não querem assumir, realizadas de maneiras extremamente precárias, que muitas vezes podem causar sérios prejuízos para a saúde, quando não a própria morte da gestante.

No entanto, o posicionamento jurisprudencial acerca do referido assunto pode apresentar diversas linhas de pensamento. Como a Apelação apresentada ao Tribunal Regional Federal da $3^{\mathrm{a}}$ Região, no processo $n^{\circ} 0002908-59.2005 .4 .03 .6103$, em que foi lhe dado provimento, um dos argumentos foi o fato de se considerar a não criminalização do aborto quando este for realizado até o terceiro trimestre de gestação. TRF-3 - ApReeNec: 00029085920054036103 SP, Relator: DESEMBARGADOR FEDERAL NELTON DOS SANTOS, Data de Julgamento: 06/06/2018, TERCEIRA TURMA, Data de Publicação: e-DJF3 Judicial 1 DATA:13/06/2018:

PROCESSUAL CIVIL E CONSTITUCIONAL. AÇÃO POPULAR. DISTRIBUIÇÃO DO MEDICAMENTO "PÍLULA DO DIA SEGUINTE" PELA REDE PÚBLICA DE SAÚDE. MÉTODO CONTRACEPTIVO. LEGALIDADE DO ATO. INEXISTÊNCIA DE LESIVIDADE AO PATRIMÔNIO PÚBLICO E À MORALIDADE ADMINISTRATIVA. MÁ-FÉ NÃO CONFIGURADA. APELAÇÃO E REMESSA NECESSÁRIA DESPROVIDAS. 1. Trata-se de ação popular ajuizada com o fito de obter declaração no sentido de que o medicamento "pílula do dia seguinte" provoca interrupção da gravidez e resulta no aborto do embrião, bem como de obter a suspensão da distribuição do fármaco pela rede pública de saúde, de entidades por ela mantidas ou conveniadas, e de todas as distribuidoras e farmácias de venda a varejo em todo o território nacional. 2. A ação popular é o meio processual disponível a qualquer cidadão que pretenda a anulação ou a declaração de nulidade de ato lesivo ao patrimônio público, à moralidade administrativa, ao meio ambiente e ao patrimônio histórico e cultural. 3. No caso em apreço, no entanto, a distribuição do fármaco "levonorgestrel" pela rede pública de saúde não configura ato lesivo concreto aos bens jurídicos descritos na Lei $n$. 4.717/1965 e no artigo $5^{\circ}$, LXXIII, da Constituição Federal. 4. A Lei n. 9.263/96, que regula o artigo 226 , $\S 7^{\circ}$, da Constituição 
Federal, dispõe que o Sistema Único de Saúde (SUS) possui o dever de garantir, em toda a rede de serviços, programa de atenção integral à saúde que inclua como atividades básicas, dentre outras, a assistência à concepção e contracepção, de modo que não há ilegalidade na comercialização/distribuição de medicamento previamente autorizado pela Agência Nacional de Vigilância Sanitária (ANVISA), como é o caso do "levonorgestrel", fármaco destinado ao planejamento familiar e à saúde da mulher. 5. Cumpre ainda asseverar que a $1^{\text {a }}$ Turma do Supremo Tribunal Federal decidiu, por maioria, no julgamento do Habeas Corpus (HC) 124306, que não há criminalização do aborto até o primeiro trimestre de gestação, diante da incompatibilidade de tal ato com os direitos fundamentais das mulheres, tais como os direitos sexuais e reprodutivos, a autonomia, e a integridade física e psíquica. 6. Percebe-se, assim, que o medicamento em questão não possui efeito abortivo, mas sim contraceptivo, de modo a impedir a fecundação do óvulo. 7. Considerando, portanto, que da distribuição do fármaco não adveio prejuízo ao patrimônio público ou lesividade à moralidade administrativa, apta a anular o ato, afigura-se correto o indeferimento dos pedidos formulados na inicial. 8. A condenação do autor popular nos ônus da sucumbência depende da demonstração de má-fé da parte, requisito disposto no artigo $5^{\circ}$, LXXIII, da CF/88, e não presente nestes autos. 9. Precedentes. 10. Apelação e remessa necessária desprovidas.

Na decisão acima, a sentença da providência a apelação, fazendose valer da argumentação baseada em não se criminalizar o aborto realizado até o terceiro mês de gestação, no tocante ao uso da pílula do dia seguinte, não a considerando método abortivo, e sim contraceptivo. Decisão, portanto, a favor da mulher decidir, desde que anteriormente ao terceiro mês de gestação, sobre a realização ou não do aborto.

O habeas corpus a seguir, que no caso não foi conhecido, trata de um caso análogo a estupro de vulnerável, encontrando-se no rol de exceções em que o aborto pode ser realizado, porém, mesmo assim não foi reconhecido, divergindo-se da decisão anterior, e do que fora anteriormente estabelecido em lei. STJ - HC: 359733 RS 2016/0157669-6, Relator: Ministro ROGERIO SCHIETTI CRUZ, Data de Julgamento: 23/08/2016, T6 - SEXTA TURMA, Data de Publicação: DJe 19/09/2016:

HABEAS CORPUS. AUTORIZAÇÃO PARA INTERRUPÇÃO DE GRAVIDEZ. ABORTO NECESSÁRIO. NÃO COMPROVAÇÃO DE RISCO DE MORTE À GESTANTE. ABORTO HUMANITÁRIO. ATO INFRACIONAL ANÁLOGO A ESTUPRO DE VULNERÁVEL. OCORRÊNCIA. VÍTIMA MENOR DE QUATORZE ANOS. VIOLÊNCIA PRESUMIDA. VULNERABILIDADE. TEMPO DE GESTAÇÃO AVANÇADO. ORDEM DENEGADA. 1. O pedido de interrupção da gravidez está alicerçado nas complicações geradas à saúde da jovem e na 
configuração do ato infracional análogo ao estupro de vulnerável, dada a presunção absoluta de violência. 2. Conquanto haja a defesa comprovado a existência de determinados fatores acidentais na gravidez da jovem, não há documento assinado por profissional da saúde que demonstre o seu iminente risco de morte. Infirmar a conclusão alcançada pela Corte de origem demandaria necessária dilação probatória, iniciativa inviável no âmbito desta ação constitucional. 3. Em que pese o caráter limítrofe da situação apresentada - um casal de namorados, ela com 13 e ele com 14 anos de idade, que, em decorrência de ato sexual consentido, enfrenta o peso de uma gravidez não desejada -, a rigor, se trata de caso de ato análogo a estupro de vulnerável (art. 217-A do Código Penal). 4. Acerca da configuração do delito em situações como a dos autos (na espécie, ato infracional análogo), por força do recente julgamento do REsp repetitivo n. 1.480.881/PI, de minha relatoria, a Terceira Seção desta Corte Superior sedimentou a jurisprudência, então já dominante, pela presunção absoluta da violência em casos da prática de conjunção carnal ou ato libidinoso diverso com pessoa menor de 14 anos. 5. A vulnerabilidade da vítima é o elemento definidor para a caracterização do delito, de modo que o fato de ser o agente ainda um adolescente não exclui a ocorrência do ato infracional. Configurada a presunção de violência, houve ato infracional análogo ao caso de estupro de vulnerável (art. 217-A do Código Penal), circunstância que, por si só, permitiria a autorização do procedimento. 6 . A gravidez encontra-se, aproximadamente, na trigésima primeira semana, de modo que, a esta altura, uma intervenção médica destinada à retirada do feto do útero materno pode representar riscos ainda maiores tanto à vida da paciente quanto à da criança em gestação. 7. Habeas corpus não conhecido.

Exemplos como estes supracitados, mostram as divergências jurisprudenciais existentes no ordenamento jurídico brasileiro, ora sendo $a$ favor ora sendo contra o aborto mesmo mediante as exceções previstas em lei, mostrando a imprecisão do sistema nesse assunto, que prejudica cada vez mais as mulheres, pois além de não encontrarem amparo caso o aborto seja sua escolha, em certas situações previstas expressamente em leis também não recebem o amparo devido, não podendo dispor de seu corpo da maneira correta, não podendo decidir sobre sua vida.

\section{CONSIDERAÇÕES FINAIS}

Através da pesquisa desenvolvida e dos dados analisados no seu decorrer, observou-se a importância do conhecimento legislativo acerca do aborto, para um melhor entendimento do que ocorre em cada caso. Observou-se a importância do estudo sobre a o inicio da personalidade jurídica, o conceito de pessoa, princípios como o da autodeterminação e da 
dignidade da pessoa humana, as dificuldades encontradas pelas gestantes, o suporte que a lei disponibiliza, as exceções em que se permitem e a maneira como seus direitos são ou não exercidos.

Os resultados evidenciam a respeito da legislação tratada em tela, e como beneficia ambos os polos, quando feita da maneira correta. Mantendo um equilíbrio entre os direitos da mãe, e do feto, para que não sejam violados em nenhuma das partes.

Restou comprovado, que, mesmo com a criminalização a prática da interrupção voluntária da gravidez acontece, sendo ela de realizada de maneira segura ou não, tendo como diferencial dessas situações, nas maiorias das vezes, a questão financeira.

Apesar de a legislação punir a pratica, tem situações em que exceções são permitidas, como a anencefalia, a gestação advinda do crime de estupro, e quando a gravidez gera grande risco de vida para a gestante. A jurisprudência apresenta opinião que diversas vezes ficou a favor da gestante que realizou o aborto entre os três primeiros meses de aborto. A criminalização do aborto tem relação direta com os conceitos de pessoa e personalidade jurídica, também com a definição de inicio da vida, que cabe a biologia, e o inicio da personalidade, sempre zelando pelo bem maior, que é a vida.

Espera-se, assim, que mais barreiras sejam ultrapassadas, que a legislação ampare sempre os dois lados, que assegure o direito a saúde da mulher, visto que a pratica é recorrente e causa de diversas mortes entre as mulheres, para que elas tenham a devida orientação, sem que seus direitos não sejam também violados, assegurando também, os direitos do nascituro.

\section{REFERÊNCIAS BIBLIOGRÁFICAS}

A EVOLUÇÃO HISTÓRICA DO ABORTO. Disponível em:

<http://www.conteudojuridico.com.br/artigo,evolucao-historica-do-aborto,56669.html>. Acesso em: 18 Jul. 2019.

ANJOS, Karla Ferraz dos. Aborto e saúde pública no Brasil: reflexões sob a perspectiva dos direitos humanos. Saúde em debate: revista do Centro Brasileiro de Estudos de Saúde, v. 37, n. 98, p. 504515, jul./set. 2013. Disponível em: 〈http://www.scielo.br/pdf/sdeb/v37n98/a14v37n98.pdf〉. Acesso em: 17 ago. 2019.

BARSTED, Leila de Andrade Linhares. Legalização e descriminalização do aborto no Brasil: 10 anos de luta feminista. Estudos Feministas, v. 0, n. 0, p. 104-130 1992. Disponível em:

<https://periodicos.ufsc.br/index.php/ref/article/view/15804>. Acesso em: 17 ago. 2019. 
CAMPO, Carmen Hein de; AMORIM, Rovena Furtado; LOYOLA, Júlia Roberta Teixeira. Aborto: análise crítica do PL 5069/2013. Sistema penal \& violência [recurso eletrônico], v. 8, n. 1, p. 65-76, jan./jun. 2016. Disponível em:

$<$ http://revistaseletronicas.pucrs.br/ojs/index.php/sistemapenaleviolencia/article/view/23928>. Acesso em: 18 jun. 2019.

Disponível em:

http://www.ambitojuridico.com.br/site/index.php?n_link=revista_artigos_leitura\&artigo_id=17585\&r evista_caderno=9. Acesso em. 16 Jun. 2019.

MAIORIA ACREDITA QUE AS MULHERES DEVEM DECIDIR SOBRE O ABORTO.

Disponível em: <http://catolicas.org.br/novidades/releases/maioria-acredita-que-as-mulheres-devemdecidir-sobre-o-aborto/>. Acesso em: 18 jul. 2019.

MATIELO, Fabrício Zamprogna. Aborto e Direito Penal. Editora Sagra dc Luzzato. 1994.

STF JÁ CONSIDEROU INCONSTITUCIONAL A CRIMINALIZAÇÃO DO ABORTO EM 2016. Disponível em: <https://agenciapatriciagalvao.org.br/destaques/stf-ja-considerou-inconstitucional-acriminalizacao-do-aborto-em-2016/>. Acesso em: 24 jul. 2019.

SUPREMO DECIDE POR 8-2 QUE ABORTO DE FETO SEM CÉREBRO NÃO É CRIME. Disponível em: <http://g1.globo.com/brasil/noticia/2012/04/supremo-decide-por-8-2-que-aborto-defeto-sem-cerebro-nao-e-crime.html>. Acesso em: 16 Jun. 2019.

VENOSA, Sílvio de Salvo. Direito Civil - Parte Geral. 13 ${ }^{\text {a }}$ Edição. São Paulo. Editora Atlas S.A. 2013. 